\title{
Decision-Making Skills and Academic Performance of Distance Education Learners: Implications for Students Counsellors
}

\author{
Nebath Tanglang and Aminu Kazeem Ibrahim
}

\begin{abstract}
The study adopted an Ex-post facto research design. The population consisted of 637 PGDDE students that were selected with the use of randomization sampling technique. 248 students were sampled for the study and the samples were grouped into two (High and Low) Decision-making skills students. The grouping was done based on the analysis of the samples responses on a standardised Students Academic Decision-making Skills Scale (SADMSS). The instruments for data collection were: Students' Academic Decision-making Skills Scale (SADMSS) and Semester Examination course result grades in four courses (Psychology of learning, Measurement and Evaluation, Sociology of Education and the Good Study Guides). The Psychometric properties of the research instruments, SADMSS were established with face and content validity and a test re-test administered after three weeks. The obtained alpha value was 0.84 while, semester examination course result grades of the four courses were moderated by External examiners appointed by the Senate of the University in the four subject areas. The study employed Pearson Product Moment Correlation coefficient statistical method to analyse the data at 0.05 level of significance. The findings indicated no statistically significant relationship between the academic performance in Psychology of learning $(r=0.013<0.901)$, Measurement and Evaluation $(r=0.086<0.391)$ and the Good Study Guide $(r=-0.029<0.77)$ except Sociology of Education $(r$ $=0.27>0.007$ ) between High and Low decision-making skills students. Implications for Student's Counsellors particularly, those serving in open and distance learning institutions were recommended.
\end{abstract}

Index Terms-Academic performance, decision-making skills, NOUN, student counsellors.

\section{INTRODUCTION}

Open and Distance Learning refers to education and training, making use of learning resources, rather than attending regular classroom session, is the central feature of the learning experience COL [1]. Open and Distance learning does not depend solely on the day-to-today or face-to-face classroom contact teaching and learning. The learning process in ODL system demands that a learner must develop an effective set of appropriate learning strategies or study skills in order to effectively study. Learning in an open and distance learning especially single mode institution is a novelistic concept in Nigeria and often many of the students are not aware of their responsibilities as distance learners and the set goals to be achieved.

The goals of Distance learners vary greatly from

Manuscript received May 20 2014; revised September 12, 2014.

The authors are with National Open University of Nigeria $14 / 16$ Victoria Island Lagos, Nigeria (e-mail: ntanglang@noun.edu.ng, aibrahim@noun.edu.ng). completing formal degree programmes at undergraduate or postgraduate levels, or even doing certificate and diploma programmes, to learning specific job related skills, to pursuing leisure interest. COL [2]. The ODL students continue learning while fulfilling commitments to work family or community. While tutors may use different strategies to facilitate group and individual learning; the goal is the same as to enable learners to develop critical thinking and effective decision-making skills to learning that meet their needs and are appropriate to the content and context. COL [1]. This observation was supported by Ranasinghe, Vidanapathirana, Rajamanthri, Gamini, and Bullumulle, [3] while stating that Distance learners typically needed a lot of training on effective decision-making techniques to be provided by counselling and guidance experts in order to complete a programme.

Students in open and distance learning must engage in different behavioural activities that are generally accepted by all psychologists to be rooted in decision-making. That is why the most widely and consistent concern is that learners in the open and distance learning must develop good decision-making skills that will help in their academic performance and achievements. In open and distance learning related courses such as the Good study guides were taught, learners support services were established with the employment of experts in counselling and guidance psychology so as to assists learners develop effective decision-making skills by most ODL institutions, these counselling and guidance psychology experts are called students counsellors in National Open University of Nigeria.

Developing effective decision-making skills is one of the goals of guidance and counselling. The process involved are efficient evaluation of problems, list of possible solutions in term of merits and demerits, application of the most appropriate solution, acceptance of the outcomes and acting upon the outcomes Shertzer and Stone [4]; Denger [5]; Okon [6]; Saka [7]; Sambo [8] and Aminu \& Gali [9].

The decision-making skills process was further supported by Mind Tools [10] a web based designed programme for measuring and training individuals on effective decision-making skills. According to the programme designers, the process include establishing a positive decision-making environment, generating potential solutions, Evaluating alternatives, Deciding, Checking the decision, Communicating and Implementing. The good thing done by the Mind Tools was that the processes were developed into an eighteen statement scale for measuring and classifying individual's decision-making skills into not fully 'matured', Ok' and 'Excellent'.

Making a good or effective decision is vital to the overall 
success of the ODL students both in academic and general life engagements. This is the pre-occupation of students' counsellors in open and distance learning. One of the major goals of Open and Distance learning is to inculcate in the learners rational decision-making skill. Ipaye [11].

Consequently, a plethora of new scholarly articles on open and distance learning emerged, examining various aspects of students personality variables for coping, adjustment and success in academic engagements. These can be seen in the following related studies. Joo, Bong \& Choi [12] examined effect of student motivation on performance in web-based instruction (WBI) and found that student's self-efficacy for self-regulated learning positively related to his / her academic self-efficacy, strategy use, and internet self-efficacy. Chan, Yum, Ran, Jegede \& Taplin [13] compared high achieving and low achieving open university students according to their study habits, purpose for learning, approaches to study, use of support systems, other commitments and self-perceptions and have discovered that motivation is a factor affecting achievement. In another study, Roblyer [14] worked on factors that motivate community college and virtually high school students to choose online or traditional course formats. The findings indicated that for students who choose distance learning, control over face and timing of learning was more important; for students who choose face-to-face (FTF) course, interaction with instructor and students was paramount. Cheners, $\mathrm{Hu}$, and Garcia [15] discovers that self-efficacy was related both to academic performance $(r=38)$ and to persistence ( $r=34$. In a similar context, Pajares, and Kranzler [16] study demonstrated that the direct effect of mathematics self-efficacy on mathematics performance $(B=349)$ was as strong as was the effect of general mental ability $(B=324)$. McIsaac, and Gurawerdena [17] opine that a combination of cognitive style, personality characteristics and self-expectations is asserted to be able to predict the achievement in distance education.

In a related study, Michael [18] examines the evidence for the effectiveness of active learning. It defines the common forms of active learning most relevant for engineering faculty and critically examines the core element of each method and found that there is broad but uneven support for the core elements of active, collaborative, cooperative and problem-based learning.

All these findings are inconclusive, but studies on relationship between decision-making skills and academic performance among open and distance learners can hardly be traced. The need to assist the ODL learners to acquire appropriate decision-making skills compatible with learning in ODL, cognitive style, personality characteristics that interplay and rooted in effective decision-making becomes necessary. Based on this, this present study investigated whether there are significant relationships in the academic performances of postgraduate diploma in distance education learners of the National Open University of Nigeria who has high and low decision-making skills, so as to draw their implications for student counsellor's consideration.

Statement of the Problem: The study is designed to investigate decision-making skills and academic performanceof distance education learners: Implication for student counsellors. The general enrolment in distance education, which is perceived as personal choice has increased tremendously in recent times but observed is the high rate of drop-out and low completion rates (National Open University of Nigeria [19] Learner may not have reflected very deeply on how their decision-making techniques affect their academic performance. One of the reasons for this can be traced to the conceptual definition of self-efficacy, Self-efficacy descriptions sees a distance learner's expectancy in his or her capability to organize and execute the behaviours needed to successfully complete a task Bandura [20]; Schunk [21] Self-efficacy beliefs can determine how people feel, think, motivate themselves, act, mechanism of change, continuing and generalizing of behaviour. Bandura. [20]. Recently implicated in the stages expected to produce an individual's effective or good decision-making skills, the "'Mind Tools [10] a web-based programme designed to measure, train and help individual develop skills needed for good decision-making incorporated the following factors: establishing a positive decision-making environment, generating potential solutions, evaluating the solutions, deciding, checking the decision in term of merits and demerits and communicating and implementing. These factors are imbedded in the characteristics expected and taught in distance learning particularly in the postgraduate diploma in distance education of the National Open University of Nigeria. Fortunately also, these variables must be the pre-entry characteristics of open and distance learning students if they must succeed and perform academically well. Due to this assumption, programme and courses were designed in distance learning, these programme or courses are aimed at developing skills of effective decision-making in distance learner, one start wondering whether these attempt has no positive result because, observed is continued increase in drop-out and low completion rates among distance learners. To buttress these points, the National Open University of Nigeria recently introduced a postgraduate programme in Distance Education for interested staff of the University without the staff paying any tuition fee but among the six hundred and thirty-seven staff that registered for the programme only three hundred and sixty-eight staff sat for first semester examination. This development can be traced to ineffective decision-making skills. Following this, there is a need to investigate the influence of decision-making skills on the academic performance of the students so that, the students counsellors will know what steps to be taking toward providing counselling service that will assist learners in developing effective decision-making skills.

\section{RESEARCH OBJECTIVE}

The following research objective was formulated for the study:

To determine whether there is a significant relationship in the academic performance in Measurement and Evaluation, Psychology of learning, Sociology of Education and the Good study guide between High and Low Decision- making skills Postgraduate Diploma in Distance Education students of NOUN.

Research Question: The following research question was formulated for the study:

Is there a significant relationship in the academic performance in Measurement and Evaluation, Psychology of 
learning, Sociology of Education and the Good study guide between High and Low Decision-making skills Postgraduate Diploma in Distance Education students of NOUN?

Research Hypothesis: The following null-hypothesis was formulated for the study:

There is no significant relationship in the academic performance in Measurement and Evaluation, Psychology of learning, Sociology of Education and the Good study guide between High and Low Decision-making skillsPostgraduate Diploma in Distance Education students of NOUN.

\section{Methodology}

Research Design: The research design adopted for this study was an Ex-post factor design. In the study, the design was used to collect responses on measures of decision-making skills. These responses were used to categorize the samples into High and Low Decision-making skills students'. The design was also used to obtain academic performances through examination and tutor-marked assignments (TMA) course result grades in Psychology of learning, Measurement and Evaluation, Sociology of Education and Good Study Guide after the students' end of semester examination in postgraduate diploma in distance education. The end of semester examination course result grades which comprises individual students total in Tutor-Marked Assignment and Examination scores all over $100 \%$. Students with grade of 1-49 are considered fail and those with 50-100 are considered pass based on NOUN standard.

Population: The population consisted of six hundred and thirty-seven (637) postgraduate students of the National Open University of Nigeria [19].

Sample and Sampling Technique: The sample consisted of two hundred and forty-eight (248) students Krejcie, and Morgan [22]. This falls into two groups. Group one is made up of one hundred and forty three (143) High decision-making skills students' and groups two is made up of one hundred and one (101) Low decision-making skills students'. The mean age, was 27.57, areas of specialization include engineering $(14=5.65 \%)$, sciences $(47=18.95 \%)$, social sciences $(73=29.44 \%)$, arts / administration $(81=32.66 \%)$, and education $(33=13.31 \%)$, years of working experiences range from 2 to 27 years and level of educational qualifications range from first degrees / higher diplomas to professorial levels and personal experience that correspond with open and distance learning because all the samples work in National Open University of Nigeria.

The sampling technique used was randomization sampling techniques based on the nature of this investigation.

Data Collection Instrument: The instruments used for data collection consisted of Students' Academic Decision-making Skills Scale (SADMSS) and End of semester examination course result grades in four courses (Psychology of learning, Measurement and Evaluation, Sociology of Education and the Good Study Guides) offered in the Postgraduate Diploma in Distance Education of the National Open University of Nigeria [19]. Decision-making Skills Scale is a scale designed by Mind Tools [10] a web-based programme for training individuals on how to make effective / good decisions. The scale consisted of eighteen statements on a format of Not at all with score of 1 , Rarely with the score of 2, Sometimes with the score of 3 , Often with the score of 4 and very often with the score of 5 , but the scoring was reversed to 5, 4, 3, 2, and 1 for statements $11,12,13,14,15,16,17$, and 18 on which the samples were to respond by honestly ticking the type that best describe their decision-making skills. Bio-data of the samples of this study was added.

The eighteen statements on the research scale measures the following skills that were theoretically believed to form good /effective decision-making skills of individuals. Shertzer and Stone [4]; Denger [5]; Okon [6], Saka [7]; Sambo [8]; Aminu, and Gali [9] and Mind Tools[10]: a) Establishing a Positive Decision-Making Environment (Statements 3, 7, 13, 16), b) Generating Potential Solutions (Statements 4, 8, 11), c)Evaluating Alternatives (Statements 1, 6, 15), d) Deciding (Statements 5, 10, 17), e) Checking the Decision (Statements 2, 9), f) Communicating and Implementing (Statements 12, 14, 18).

Score interpretation of Students' Academic Decision-making Skills Scale: PGDDE student with score range of 18 to 50 is interpreted as Low decision- making skills while PGDDE students with score range of 51 to 90 is interpreted as High decision-making skills students.

Validation of the Research Instrument: The Psychometric properties of SADMSS were established through face and content validity on a pilot study that involved 50 postgraduate students of Distance learning of the National Teachers Institute of Nigeria. A test re-test conducted after three weeks of the first administration gives a coefficient alpha value of 0.84 . For the individual items that measures the processes involved in making an effective decision, the following Cronbach alpha reliability estimates were obtained: a) Establishing a positive decision-making environment $=0.62$; b) Generating potential solutions $=0.72$, c)Evaluating alternatives $=0.80$, d) Deciding $=0.74$, e) Checking the decision $=0.80$, f) Communicating and implementing $=0.799$. These individual items alpha values indicated their suitability for the study. While, the validation of the 2013/2014 semester examination for the four courses being the academic performance were established by External Examiners in the subject areas appointed by the Senate of the National Open University of Nigeria.

Administration and Collection of Research Instruments: The researchers were personally involved in the administration of the research instruments being staff of NOUN and also, personally collected and compiled the required academic performance data.

Methods of Data Analysis: The researchers employed both descriptive and inferential statistics for data analysis. The relationships between the semester examination course result grades of high and low decision-making skills students were analysed with the use of Pearson product moment correlation coefficient statistical method at 0.05 level of significance. SPSS version 20.0 was utilized in the computation.

\section{RESUlts}

For the purpose of objective analysis, data of one hundred and one (101) randomly selected high decision-making samples were correlated with the one hundred and one 
identified Low decision-making samples. The results are hereby presented in tables $\mathrm{i}$ to $\mathrm{v}$. The interpretation of each result follows the tables:

TABLE I: SAMPLES’ RESPONSES ON MEASUREMENT AND EVALUATION, PSYCHOLOGY OF LEARNING, THE GOOD STUDY GUIDE AND SOCIOLOGY OF

\begin{tabular}{|c|c|c|c|c|}
\hline \multicolumn{5}{|c|}{ EDUCATION $(N=202)$} \\
\hline $\mathrm{M} \& \mathrm{E}$ & PL & SE & & \\
\hline $\mathrm{S} / \mathrm{n}$ & L- H & $\mathrm{L} \mathrm{H}$ & $\mathrm{L} \mathrm{H}$ & $\mathrm{L} \mathrm{H}$ \\
\hline 1 . & $50-62$ & $30-56$ & $53-56$ & $53-34$ \\
\hline 2. & $50-50$ & $42-20$ & $21-45$ & $75-58$ \\
\hline 3. & $55-70$ & $74-56$ & $50-63$ & $63-71$ \\
\hline 4. & $38-56$ & $47-69$ & $70-72$ & $50-61$ \\
\hline 5. & $51-72$ & $9-15$ & $62-4$ & $58-54$ \\
\hline 6. & $54-35$ & $65-42$ & $53-44$ & $50-59$ \\
\hline 7. & $36-33$ & $28-16$ & $56-68$ & $38-62$ \\
\hline 8. & $66-52$ & $51-72$ & $16-7$ & $26-63$ \\
\hline 9. & $51-56$ & $43-56$ & $7-71$ & $24-43$ \\
\hline 10. & 66- 68 & $11-19$ & $55-52$ & $38-87$ \\
\hline 11. & $62-50$ & $20-55$ & $63-61$ & $59-51$ \\
\hline 12. & $56-64$ & $19-60$ & $70-47$ & $38-55$ \\
\hline 13. & $62-62$ & $63-51$ & $50-18$ & $87-77$ \\
\hline 14. & $33-34$ & $45-45$ & $57-19$ & $44-78$ \\
\hline 15. & $52-42$ & $67-46$ & $59-52$ & 64-71 \\
\hline 16. & $58-71$ & $63-18$ & $69-49$ & $51-56$ \\
\hline 17. & $55-70$ & $66-17$ & $43-55$ & $42-39$ \\
\hline 18. & $72-42$ & $59-73$ & $50-49$ & $90-53$ \\
\hline 19. & $51-55$ & $72-27$ & $47-62$ & $63-65$ \\
\hline 20. & $45-50$ & $10-54$ & $57-7$ & $84-50$ \\
\hline 21. & $32-40$ & $47-80$ & $55-8$ & $50-67$ \\
\hline 22. & $50-66$ & 89-59 & $19-56$ & 51-59 \\
\hline 23. & $55-61$ & $82-74$ & $52-67$ & $38-20$ \\
\hline 24. & $63-62$ & $72-58$ & 49-10 & $65-52$ \\
\hline 25. & $62-58$ & $29-30$ & $64-7$ & $38-51$ \\
\hline 26. & $42-70$ & $52-30$ & $50-20$ & $50-71$ \\
\hline 27. & $58-60$ & $47-30$ & $58-53$ & $43-52$ \\
\hline 28. & $43-57$ & $71-56$ & $55-17$ & $74-59$ \\
\hline 29. & $65-55$ & $56-44$ & $70-58$ & $53-81$ \\
\hline 30. & $50-56$ & $54-30$ & $39-72$ & $36-51$ \\
\hline 31. & $50-42$ & $50-30$ & $35-37$ & $60-56$ \\
\hline 32. & $54-54$ & $59-25$ & $66-35$ & $52-53$ \\
\hline 33. & $54-61$ & $9-82$ & $43-20$ & $50-42$ \\
\hline 34. & $66-52$ & $66-53$ & 47-71 & $72-64$ \\
\hline 35. & $55-50$ & $20-75$ & $63-67$ & $75-38$ \\
\hline 36. & $61-61$ & $81-30$ & $69-78$ & $55-50$ \\
\hline 37. & $50-52$ & $26-48$ & $63-48$ & $50-67$ \\
\hline 38. & $56-50$ & $67-67$ & $19-16$ & $52-39$ \\
\hline 39. & $65-61$ & $54-42$ & $65-61$ & $62-76$ \\
\hline 40. & $54-43$ & $82-62$ & $77-61$ & $52-59$ \\
\hline 41. & $68-53$ & $74-49$ & $44-68$ & $36-84$ \\
\hline 42. & $59-52$ & $29-29$ & 54-18 & $50-67$ \\
\hline 43. & $61-53$ & $70-54$ & $11-65$ & $42-71$ \\
\hline 44. & $40-52$ & $58-60$ & $69-51$ & $85-69$ \\
\hline 45. & $58-42$ & $49-60$ & $39-18$ & $50-50$ \\
\hline 46. & $44-42$ & $18-55$ & $70-72$ & $51-57$ \\
\hline 47. & $56-58$ & $29-34$ & $45-55$ & $58-68$ \\
\hline 48. & $73-57$ & $48-52$ & $62-71$ & $58-61$ \\
\hline 49. & $32-72$ & $22-57$ & $66-52$ & $58-74$ \\
\hline 50. & $72-61$ & $19-55$ & $56-69$ & $52-34$ \\
\hline 51. & $44-51$ & 89-18 & 07-05 & $68-55$ \\
\hline 52. & $34-65$ & $44-50$ & $67-60$ & $87-67$ \\
\hline 53. & $76-52$ & $77-29$ & 59-09 & $64-71$ \\
\hline 54. & $62-66$ & $63-25$ & $62-54$ & $62-64$ \\
\hline 55. & $55-42$ & $8-28$ & $73-61$ & $82-62$ \\
\hline 56. & $50-40$ & $71-9$ & $64-56$ & $89-61$ \\
\hline 57. & $50-64$ & $59-51$ & $22-52$ & $38-73$ \\
\hline 58. & $53-52$ & $40-32$ & 01-19 & $38-51$ \\
\hline 59. & $53-56$ & $29-58$ & $68-69$ & 54-69 \\
\hline 60. & $41-56$ & $54-77$ & $22-20$ & $19-69$ \\
\hline 61. & $60-54$ & $18-42$ & $10-62$ & $59-69$ \\
\hline 62. & $50-57$ & $65-40$ & $60-77$ & $58-65$ \\
\hline 63. & $32-58$ & $72-30$ & $14-39$ & $63-58$ \\
\hline 64. & $68-50$ & $17-64$ & $21-38$ & $67-61$ \\
\hline 65. & $64-56$ & $90-17$ & $10-60$ & $44-65$ \\
\hline 66. & $71-54$ & $56-72$ & 31-19 & $33-67$ \\
\hline 67. & $62-50$ & $30-24$ & $59-47$ & $53-52$ \\
\hline 68. & $56-56$ & $5-24$ & $46-64$ & $40-58$ \\
\hline 69. & $57-60$ & $56-6$ & $60-70$ & $65-53$ \\
\hline 70. & $73-58$ & $87-50$ & $48-76$ & $63-63$ \\
\hline
\end{tabular}

\begin{tabular}{|c|c|c|c|c|}
\hline 71. & $44-43$ & $20-76$ & $42-44$ & $72-62$ \\
\hline 72. & $50-55$ & $71-29$ & $55-18$ & $67-38$ \\
\hline 73. & $57-51$ & $73-66$ & $07-66$ & $37-64$ \\
\hline 74. & $53-36$ & $30-62$ & $55-65$ & $50-80$ \\
\hline 75. & $40-51$ & $30-30$ & $56-67$ & $32-88$ \\
\hline 76. & $50-33$ & $16-85$ & $66-77$ & $60-68$ \\
\hline 77. & $50-66$ & $63-62$ & $47-49$ & $50-71$ \\
\hline 78. & $50-61$ & $55-62$ & 06-06 & $54-44$ \\
\hline 79. & $66-35$ & $17-29$ & $70-68$ & $50-55$ \\
\hline 80. & $65-55$ & $60-31$ & $12-60$ & $52-66$ \\
\hline 81. & $54-41$ & $48-73$ & 46-68 & $39-51$ \\
\hline 82. & $53-38$ & $56-63$ & $52-41$ & $54-77$ \\
\hline 83. & $44-50$ & $28-68$ & $38-20$ & $76-70$ \\
\hline 84. & $64-55$ & $51-30$ & 21-08 & $61-56$ \\
\hline 85. & $54-33$ & $30-49$ & $74-32$ & $51-67$ \\
\hline 86. & $66-42$ & $59-29$ & $55-68$ & $77-47$ \\
\hline 87. & $43-34$ & $39-49$ & $19-09$ & $55-56$ \\
\hline 88. & $57-57$ & $63-30$ & $49-09$ & $52-62$ \\
\hline 89. & $56-70$ & $66-74$ & $47-56$ & $58-62$ \\
\hline 90. & $57-56$ & $19-30$ & $39-56$ & $67-82$ \\
\hline 91. & $56-54$ & $54-26$ & $53-64$ & $66-54$ \\
\hline 92. & $42-62$ & $18-25$ & $72-69$ & $80-67$ \\
\hline 93. & $50-52$ & $73-69$ & $73-51$ & $78-37$ \\
\hline 94. & $55-51$ & $52-85$ & $10-05$ & $57-53$ \\
\hline 95. & $71-51$ & $50-30$ & $16-63$ & $51-82$ \\
\hline 96. & $56-50$ & $39-30$ & $62-63$ & $69-55$ \\
\hline 97. & $58-50$ & $63-71$ & $61-60$ & $55-32$ \\
\hline 98. & $57-55$ & $9-20$ & $67-07$ & $65-34$ \\
\hline 99. & $53-35$ & $43-68$ & $51-60$ & $61-52$ \\
\hline 100. & \multicolumn{4}{|c|}{$56-50 \quad 34-42 \quad 66-73 \quad 79-72$} \\
\hline 101. & $54-57$ & $50-71 \quad 0$ & $6-46 \quad 4$ & -61 \\
\hline
\end{tabular}

Table I showing samples' responses on measurement and evaluation, psychology of learning, the good study guide and sociology of education $(N=202)$.

Keys: $\mathrm{ME}=$ Measurement and evaluation, $\mathrm{PL}=$ Psychology of learning. GSG= the Good study guide. $\mathrm{SE}=$ Sociology of Education. $\mathrm{H}-\mathrm{L}=\mathrm{High}$ and Low decision-making skills

Hypothesis 1: There is no significant relationship in the academic performance in Measurement and Evaluation between High and Low Decision-making skills PGDDE students of NOUN.

TABLE II: CORRELATION ANALYSIS FOR HIGH AND LOW DECISION-MAKING SKILLS STUDENTS’ ACADEMIC PERFORMANCE IN MEASUREMENT AND EVALUATION $(N=202)$

\begin{tabular}{|lccccc|}
\hline \multicolumn{7}{l}{ Variables } & $N$ & $\chi$ Sds & $r$-value & \\
$\begin{array}{l}\text { High } \\
\text { decision-making }\end{array}$ & & & & & \\
$\begin{array}{l}\text { Skills students } \\
\text { Low }\end{array}$ & 101 & 54.49 & 9.74 & 0.086 & 0.391 \\
$\begin{array}{l}\text { decision-making } \\
\text { Skills students }\end{array}$ & 101 & 53.21 & 9.73 & & \\
\hline
\end{tabular}

Table II show that there is no significant relationship between the academic performance in Measurement and Evaluation of High and Low decision-making skills students.. The analysis shows $r$-value of 0.086 at asymptotic level of 0.391 (2-tailed) is not statistically significant. Therefore the hypothesis is accepted.

Hypothesis 2: There is no significant relationship in the academic performance in Psychology of Education between High and Low Decision-making skills PGDDE students of NOUN.

Table III: show that, there is no significant relationship between the academic performance in Psychology of Learning of High and Low decision-making skills students. The analysis shows $r$-value of 0.013 at asymptotic level of 0.901 is not statistically significant. Therefore the hypothesis is accepted.

Hypothesis 3: There is no significant relationship in the 
academic performance in Sociology of Education between High and Low Decision-making skills PGDDE students of NOUN.

TABLE III: CORRELATION ANALYSIS FOR HIGH AND LOW DECISION-MAKING SKILlS STUDENTS'ACADEMIC PERFORMANCE IN PSYCHOLOGY OF LEARNING $(N=202)$

\begin{tabular}{|lcccc|}
\hline Variables & $N$ & $\chi$ Sds & $r$-value \\
$\begin{array}{l}\text { High } \\
\text { decision-making }\end{array}$ & & & & \\
$\begin{array}{l}\text { Skills students } \\
\text { Low }\end{array}$ & 101 & 47.74 & 22.13 & 0.013 \\
$\begin{array}{l}\text { decision-making } \\
\text { Skills students }\end{array}$ & 101 & 46.95 & 19.49 & \\
\hline
\end{tabular}

TABLE IV: CORRELATION ANALYSIS FOR HIGH AND LOW DECISION-MAKING SKILls STUDENTS' ACADEMIC PERFORMANCE IN

\begin{tabular}{|lcccc|}
\multicolumn{5}{c}{ SOCIOLOGY OF EDUCATION $(N=202)$} \\
\hline Variables & $N$ & $\chi$ Sds & $r$-value \\
High & & & & \\
decision-making & & & & \\
$\begin{array}{l}\text { Skills students } \\
\text { Low }\end{array}$ & 101 & 47.22 & 20.28 & 0.27 \\
decision-making & & & & \\
Skills students & 101 & 46.60 & 22.79 & \\
\hline
\end{tabular}

Table IV shows that there is a significant relationship between the academic performance in Sociology of Education of High and Low decision-making skills students. The analysis shows $r$-value of 0.27 at asymptotic level of 0.007 (2-tailed) is statistically significant. Therefore the hypothesis is rejected. .

Hypothesis 4: There is no significant relationship in the academic performance in Good Study Guide between High and Low Decision-making skills PGDDE students of NOUN.

TABLE V: CORRELATION ANALYSIS FOR HIGH AND LOW DECISION-MAKING SKILLS STUDENTS’ ACADEMIC PERFORMANCE IN THE GOOD STUDY GUIDES $(\mathrm{N}=202)$

\begin{tabular}{|lcccc|}
\hline Variables & $N$ & $\chi$ Sds & $r$-value \\
$\begin{array}{l}\text { High } \\
\text { decision-making }\end{array}$ & & & & \\
$\begin{array}{l}\text { Skills students } \\
\text { Low }\end{array}$ & 101 & 59.77 & 12.895 & -0.029 \\
$\begin{array}{l}\text { decision-making } \\
\text { Skills students }\end{array}$ & 101 & 56.23 & 14.85 & \\
\hline
\end{tabular}

Table $\mathrm{V}$ shows a negative relationship between the academic performance in Good Study Guide of High and Low decision-making skills students. The analysis shows $r$-value of -0.029 at asymptotic level of 0.77 (2-tailed) is not statistically significant. Therefore the hypothesis is accepted.

\section{DISCUSSION}

The research findings indicated no statistically significant relationship between the academic performance in Measurement and Evaluation, Psychology of learning, and Good Study Guide except Sociology of Education between High and Low decision-making skills students of postgraduate in Distance Education of the National Open University of Nigeria. Overall, the results of the non-statistically significant relationship between High and Low decision-making skills students as surfaced in the academic performance in Measurement and Evaluation, Psychology of learning and the Good Study Guide and significant relationship of decision-making skills of High and Low students in Sociology of Education respectively could be attributed to other extraneous factors. Such factors include the high age level that correspond with individual maturity, areas of specialization, personal experience and level of education that existed among the two groups which were in-built in this present study and were captured in the research measuring scale and mentioned earlier in the work when describing the sample of the study characteristics, and were also quoted from the opinion of McIsaac \& Gurawerdena [17] that a combination of cognitive style, personality characteristics and self-expectations is asserted to be able to predict the decision-making pattern and achievement in distance education, this was part of the reviewed literature.

The finding of this study agrees with Joo, Bong \& Choi [12] that discovered the effect of student motivation on performance in web-based instruction (WBI) as earlier mentioned. Chan, Yum, Ran, Jegede \& Taplin [13] that compared high achieving and low achieving Open University students according to their study habits, purpose for learning, approaches to study, use of support systems, other commitments and self-perceptions. In another study, Roblyer [14] investigated factors that motivate community college and virtually high school students to choose online or traditional course formats. Also, Cheners, Hu, and Garcia [15] found that self-efficacy was related to academic performance. Pajares \& Kranzler [16] study on direct effect of mathematics self-efficacy on mathematics performance. Although, these were not surprising, because there will exist a strong positive correlation between positive self-efficacy and effective decision-making skills of individual.

The finding that a significant relationship existed in academic performance in Sociology of Education between High and Low decision-making skills students disagrees with the finding of Michael [18] that studied on-line learning environments that was also mentioned earlier. Similarly, self-efficacy beliefs are rooted in effective decision-making skills but broad in scope.

\section{IMPLICATIONS FOR COUNSELLING}

The implications of these findings towards ensuring students' acquisition of appropriate decision-making skills and techniques from students' counsellors, particularly in open and distance learning are many, first it provide instrument for diagnosing the level of decision-making skills or techniques of student client that may be responsible for poor academic performance, it also suggest the incorporation and consideration of student client age, level of maturity, areas of specialization, personal experience and level of education or what the researchers accepted as a combination of cognitive style, personality characteristics and self-expectations, that are extraneous but usually interplay with decision-making skills of student clients, in addition, the variables will assist in selection of appropriate wordings to be used in developing appropriate items for measuring decision-making level of student client before establishing rapport and administering counselling services. Noted also, was the combination of cognitive style, personality characteristics and self-expectations, will help the student counsellor appreciate individual differences that exist in making effective decision. Second, the process of assisting 
students client in developing effective decision-making skills, student counsellor should considered this as one of the core responsibility in open and distance education; third the students' counsellors need a variety of programmes for acquiring the skills for training students in acts of effective decision-making.

\section{CONCLUSION}

The authors suggested further study that will investigate a combination of cognitive style, personality characteristics and self-expectations on students' decision-making skills.

\section{ACKNOWLEDGMENT}

The authors are extremely grateful to many of the authors and publishers we cited or quoted from their works, and if anything is inadvertently adopted or adapted where permission should have been obtained, it is hoped that this will be excused as an oversight. The authors also thank the staff of the National Open University of Nigeria that voluntarily participated in the study and the Management of the National Open University of Nigeria for given permission to reach the staff.

\section{REFERENCES}

[1] An Overview Of Open And Distance Learning, A Training Toolkit, COL in co-operation with the Asian Development Bank and the International Extension College in the United Kingdom, 2002, pp. 45-53.

[2] Tutoring in Open and Distance Learning, A Handbook for Tutors, Commonwealth of Learning, Vancouver, BC V6H3X8 Canada, 2003, pp. 74-83.

[3] S. Ranasinghe, U. Vidanapathirana, S. Rajamanthri, L. P. S. Gamini, and K. Bullumulle, "An evaluation of learners' perception of students supports services in the Faculty of humanities and social sciences," OUSL Journal, vol. 5, pp. 22-40, 2009.

[4] B. Shertzer and S. C. Stone, Fundamentals of Guidance, Boston: Houghton Mifflin Company, 1976, ch. 1, pp. 33-39.

[5] D. L. Denger, Guidance and Counselling in Non-school Setting, Jos Nigeria: Savanna Publishers Limited, 1986, ch. 1, pp 21-33.

[6] S. E. Okon, Guidance for the 6-3-3-4 System of Education, Institute of Education, Ahmadu Bello University, Zaria Nigeria, 1984, ch. 4, pp. 37-41.

[7] A. Y. O. Saka, A Collection of Essay in Guidance and Counselling for Schools, Debis-co Printing and Press, Kano Nigeria, 1996, ch. 4, pp. 20-29.

[8] S. Sambo, Understanding Guidance and Counselling, Zaria Nigeria: Ahmadu Bello University Press Limited, 2008, ch. 3, pp. 47-51.

[9] K. I. Aminu and S. Gali, Guidance and Counselling in Schools: Theories and Practices, Kano Nigeria: Albarka Publishing Company, 2012, ch. 2, pp. 74-76.

[10] Mind Tools. (February 2014). Making an effective decision. MINDTOOLS. [Online]. Available: http:/www.mindtools.com/pages/article/newTED-79htm

[11] B. Ipaye, Strategies for Sustainable Learners Support Services in Developing Nations, Nigeria: National Open University of Nigeria, 2007, ch. 7, pp 111-117.

[12] Y. J. Joo, M. Bong, and H. J. Choi, "Self-efficacy for self-regulated learning, academic self-efficacy and internet self-efficacy in web-based instruction," Educational Technology Research and Development, vol. 48, no. 2, pp. 5-17, February 2000.

[13] M. S. C, Chan, J. Yum, R. Y. K. Fan, O. Jegede, and M. Taplin, "Locus of control and meta cognition in open and distance learning: A comparative study of low and high achievers," presented at the 13th. Annual Conference, Asian Association of Open Universities. The Central Radio \& TV University, Beijing, China, October 9-12, 1999.
[14] M. D. Roblyer, "Is choice important in distance learning? A study of student motives for taking internet-based courses at the high school and community college levels," Research on Computing in Education, vol. 32, no. 1, pp. 157-172, June 1999.

[15] M. M. Chemers, L. Hu, and B. F. Garcia, "Academic self-efficacy and first-year college student performance and adjustment," Educational Psychology, vol. 93, no. 1, pp. 55-64, February 2001.

[16] F. Pajares. (February 2002). Self-efficacy beliefs in academic contexts. [Online]. http://www.emory.edu/EDUCATION/mfp/efftalk.html

[17] M. S. Mc Isaac, and C. N. Gunawardena, 'Distance Education,' New York: Macmillan, 1996, pp. 403-437.

[18] P. Michael, "Does active learning work? A review of the research," Engineering Education, vol. 93, no. 3, pp. 223-231, July 2013.

[19] National Open University of Nigeria, Convocation Booklet, Nigeria, 2013, ch. 2, pp 19-26.

[20] A. Bandura, "Self-efficacy: The exercise of control," Educational Psychologist, vol. 28, pp. 117-148, August 1997.

[21] D. H. Schunk, "Self-efficacy and academic motivation," Educational Psychologist, vol. 26, no. 3-4, pp. 207-237, August 1991.

[22] R. V. Krejcie and D. V. Morgan. (February 1970). Determining sample size for research activities Educational and psychological measurement. [Online]. Available: http:/www.kenpro.org/sample-size-determination-using-krejcie-andmorgan-table

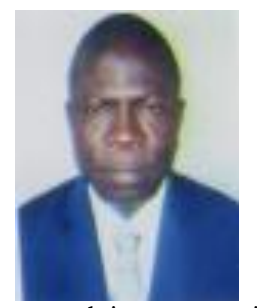

Nebath Tanglang was born in Tanglang Town, Gombe State of Nigeria on the $8^{\text {th }}$ of August 1956. He earned his $\mathrm{PhD}$ in sports management at Ahmadu Bello University Zaria Nigeria in 2003.

He was the head of the Department of Physical and Health Education, University of Maiduguri, Borno State Nigeria between 2005 and 2007. He is the deputy vice chancellor administration of the National Open University of Nigeria, Lagos. His current research interests are in support services to distance learners in Nigeria and he had previously worked on Corporate Sport Sponsorship in Nigeria.

Professor Tanglang is a member of North America Society for Sport Management, African Council for Distance Education, Society for Sport Management and Sport Psychology Association of Nigeria (SPAN) Professional. He has earned several merit awards for meritorious services in the Department of Physical and Health Education and Faculty of Education, University of Maiduguri Borno State Nigeria in 2005 and 2007. He has also earned a meritorious award for an outstanding achievement in the field of Education awarded by His Royal Highest, Abdu BubaMaisheru 11, and the $15^{\text {th }}$ Mai Tangle in 2008, and a merit award for a distinguished achievement in Education by the National Association of Tangle Students, University of Maiduguri in 2006. He works as Member Editorial of Sport and Arts, Horizon Research Publishing, USA and has served on several Senate committees of the National Open University of Nigeria.

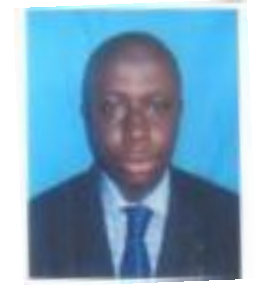

Kazeem Ibrahim Aminu was born in Kaduna State which is an indigene of Ikorodu Local Government Area of Lagos State, Nigeria on the $27^{\text {th }}$ of April 1974. He earned his $\mathrm{PhD}$ in educational psychology at Bayero University Kano Nigeria in 2010.

$\mathrm{He}$ is a lecturer in the Department of Psychology and Counseling, Federal College of Education, Kano Nigeria between 2004 and 2013. He is presently a senior lecturer in the School of Education and Students Counselor in the Directorate of Learner Support Services of the National Open University of Nigeria, Lagos. His current research interests are in secondary school student's violent behaviour and psychotherapy, and he had previously worked on Influence of face-to-face facilitation on students' academic performance among Distance Learners in Nigeria.

Dr. Aminu is a member of Nigerian Society for Educational Psychologists, Counseling Association of Nigeria, and African Council for Distance Education and the Teachers Registration Council of Nigeria. He won the Federal Government of Nigeria Scholarship award for Postgraduate studies in 2002. He works as Official member of the Students Counseling Centre, Federal College of Education, Kano Nigeria between 2010 and 2012, Member Editorial Review Board of the Federal College of Education, Kano Nigeria between 2012 and 2013. 